\title{
Impact of selected genetic factors on clopidogrel inactive metabolite level and antiplatelet response in patients after percutaneous coronary intervention
}

\author{
Urszula Adamiak-Giera ${ }^{1}$ (D) Anna Czerkawska ${ }^{1} \cdot$ Szymon Olędzki ${ }^{2} \cdot$ Mateusz Kurzawski $^{3} \cdot \mathrm{Krzysztof} \mathrm{Safranow}^{4}$. \\ Maria Jastrzębska ${ }^{5}$ Barbara Gawrońska-Szklarz ${ }^{1}$
}

Received: 4 June 2020 / Revised: 11 November 2020 / Accepted: 16 November 2020 / Published online: 3 December 2020

(c) The Author(s) 2020

\begin{abstract}
Background and objective Clopidogrel is frequently used as part of optimal dual antiplatelet therapy in high-bleeding risk patients with the acute coronary syndrome. The concentration of the inactive carboxylic acid metabolite of clopidogrel might be useful to evaluate the response to clopidogrel therapy. Therefore, we sought to correlate the inhibition of platelet aggregation with the plasma level of the inactive metabolite of clopidogrel in patients after percutaneous coronary interventions (PCI) and their associations with the most frequently studied genetic polymorphisms. For this purpose, the fast and simple HPLC method for determining the concentration of the inactive metabolite was developed.

Methods The effect of CYP2C19, CYP3A4/5, ABCB1 and PON1 genes on the plasma inactive metabolite concentration of clopidogrel and the platelet aggregation was investigated in 155 patients before and after PCI.

Results The concentration of the inactive metabolite of clopidogrel was not significantly different in the intermediate metabolizers (IM) of CYP2C19 compared with extensive metabolizers (EM) both before and after PCI, while inhibition of platelet aggregation was found to be significantly better in EM than in IM. The presence of the A allele at position 2677 in the $A B C B 1$ gene was associated with a significantly lower concentration of inactive metabolite of clopidogrel before PCI. Conclusion The CYP2C19*2 allele was associated with decreased platelet reactivity during clopidogrel therapy before and after PCI. Simultaneous determination of platelet aggregation and concentration of the inactive clopidogrel metabolite may be useful in clinical practice to find the cause of adverse effects or insufficient treatment effect in patients chronically treated with clopidogrel.
\end{abstract}

Keywords Clopidogrel inactive metabolite $\cdot$ Concentration $\cdot$ Genetic polymorphisms

\section{Introduction}

Urszula Adamiak-Giera

uadamiak@pum.edu.pl

1 Department of Pharmacokinetics and Therapeutic Drug Monitoring, Pomeranian Medical University, Szczecin, Poland

2 Department of Cardiology, Pomeranian Medical University, Szczecin, Poland

3 Department of Experimental and Clinical Pharmacology, Pomeranian Medical University, Szczecin, Poland

4 Department of Biochemistry and Medical Chemistry, Pomeranian Medical University, Szczecin, Poland

5 Department of Laboratory Diagnostics and Molecular Medicine, Pomeranian Medical University, Szczecin, Poland
Current guidelines recommend potent platelet inhibition with ticagrelor or prasugrel in patients after an acute coronary syndrome [1-3]. However, optimal dual antiplatelet therapy strategy in high-bleeding risk patients presenting with acute coronary syndrome remains debated. Gragnano et al. [4] showed that clopidogrel, rather than potent P2Y12 inhibitors, is frequently used of as part of dual antiplatelet therapy in real-world high-bleeding risk patients presenting with acute coronary syndromes. Although current guidelines do not recommend the use of clopidogrel over ticagrelol in high bleeding risk patients presenting with acute coronary syndrome, several registries have shown that clopidogrel is frequently preferred by clinicians in this setting [4-7]. As shown in clinical trials clopidogrel effectively lowers the 
occurrence of myocardial infarction, ischemic stroke, and vascular death in patients [7-9]. Despite the obvious advantages of clopidogrel, many clinical studies have shown that approximately $5-40 \%$ of patients treated with standard doses of clopidogrel display inadequate antiplatelet responses [10, 11]. A range of $30-90 \%$ of variability noted in the pharmacokinetics and pharmacodynamics, particularly absorption and metabolism, are considered attributable to pharmacogenomic variation $[10,11]$. Current evidence demonstrates that adherence to secondary prevention medication in acute coronary syndromes is suboptimal across the globe in terms of both persistence with treatment and compliance with dosing instructions throughout the recommended duration of treatment. Non-adherence to oral antiplatelet medications is associated with worse outcomes or failure of therapy [12].

Clopidogrel is a pro-drug that has to be converted to an active metabolite by hepatic cytochrome P450 (CYP) isoenzymes to inhibit platelet aggregation. It is also subject to efflux via P-glycoprotein (encoded by ABCB1, also known as MDR1). ABCB1 polymorphism may affect drug transport and efficacy. Approximately $85 \%$ of the orally administered drug is hydrolyzed by esterases in the blood into an inactive carboxylic acid derivative. The remaining drug (about 15\%) is bioactivated in a two-step oxidative process by CYP450 isoenzymes in the liver to an active metabolite that selectively and irreversibly inhibits the ADP P2Y12 receptor on platelet cell [10, 13, 14]. A number of functional polymorphisms of the CYP450 enzymes have been shown to affect the metabolism of clopidogrel. The CYP2C19 enzyme plays an important role in the hepatic bioactivation of clopidogrel. A large number of clinical studies have documented that a loss-of-function variant CYP2C19*2 affects clinical profiles of clopidogrel (efficacy and safety). Moreover, the presence of the CYP2C19*17 variant might lead to an increased response to clopidogrel, but carriers of the variant have an increased risk of developing bleeding as well [10, 15-18]. The activation of clopidogrel is partly governed by the CYP3A system, which consists of 3A4 and 3A5 isoenzymes $[10,16]$. According to Kazui et al. [14] CYP3A4 is responsible for the transformation of $39.8 \%$ of the intermediate product of clopidogrel. Therefore, altered activity of CYP3A4 resulting from genetic polymorphisms might have an influence on the yield of active metabolite formation and on the antiplatelet effect of clopidogrel. Clopidogrel metabolism can also be influenced by genetic variants in other proteins, such as ABCB1, paraoxonase-1 (PON1), carboxylesterase (CES1), and P2Y12 receptors [10, 13, 17-20]. These genetic variants can interfere with the regulation of gene transcription, protein translation, or substrate affinity. As shown in the literature, Q192R (A576G) genetic variant of paraoxonase-1 (PON1), an esterase synthesized in the liver and present in the serum, was reported to be strongly involved in clopidogrel bioactivation and clopidogrel responsiveness
$[19,20]$. These results were in contrast to the Fontana et al. [21] who reported no relationship of the PON1 (Q192R) polymorphism with clinical effects of clopidogrel. Campo et al. [22] demonstrated that PON1 Q192R genotype has a minimal influence on-clopidogrel platelet reactivity variation over time. Other genetic polymorphisms occurring in the gene sequences are also considered as potential factors of the variable response of clopidogrel. Furthermore, polymorphisms in the $A B C B 1$ may influence cell efflux of clopidogrel, resulting in varied drug bioavailability and response [10, 23, 24]. As shown, ABCB1 3435 TT genotype might be associated with lower exposition to the parent drug [24].

The active metabolite of clopidogrel is a very labile molecule that degrades rapidly in blood after sample collection [25], therefore determination of the concentration of the inactive carboxylic acid metabolite of clopidogrel might be useful to evaluate the response to clopidogrel therapy. Serebruany et al. [26] showed that the plasma level of inactive carboxylic acid metabolite but not the level of the active metabolite of clopidogrel is a useful marker for monitoring compliance to clopidogrel in registries and clinical trials.

We aimed to investigate the contribution of the most studied $C Y P 2 C 19, C Y P 3 A 4 / 5, P O N 1$, and $A B C B 1$ polymorphisms to the plasma level of an inactive carboxylic acid metabolite of clopidogrel and antiplatelet response. For this purpose, the fast and simple HPLC method for determining the concentration of the metabolite was developed. We wanted to assess whether the level of inactive carboxylic acid metabolite determined in one sample at steady-state can be used as a marker to evaluate the antiplatelet effect of clopidogrel in patients after PCI and patients' compliance with clopidogrel therapy.

\section{Experimental}

\section{Patients and sample collection}

The study included 155 patients (45 female, 110 male) and was conducted in the Department of Cardiology with Intense Cardiac Care (Pomeranian Medical University in Szczecin, Poland). Presented prospective research was approved by the ethics committee at Pomeranian Medical University in Szczecin and written informed consent was obtained from all subjects. Patients received oral clopidogrel as a $75 \mathrm{mg}$ maintenance dose and $75 \mathrm{mg}$ acetylsalicylic acid (ASA) for minimum 7 days prior to the percutaneous coronary intervention procedure (PCI). The persons qualified for the study applied for the performance of the coronarography within the prescribed period. $24 \mathrm{~h}$ after this study, a sample of whole peripheral blood was collected at $200 \mu \mathrm{L}$ to determine 
selected polymorphisms of the genes $C Y P 2 C 19, C Y P 3 A 4$, CYP3A5, ABCB1, and PON1.

On the established day of PCI procedure, the patients who were enrolled in the study took clopidogrel $75 \mathrm{mg}$ and acetylsalicylic acid $75 \mathrm{mg}$. Blood samples for quantification of plasma concentrations inactive metabolite of clopidogrel were collected at $2 \mathrm{~h}$ after oral administration of a tablet containing $75 \mathrm{mg}$ clopidogrel. A $4 \mathrm{~mL}$ of blood was drawn into collection systems containing $\mathrm{K}_{2}$ EDTA as the anticoagulant and then were centrifuged at $1500 \times g$ for $10 \mathrm{~min}$. Obtained plasma samples were stored at $-25{ }^{\circ} \mathrm{C}$ until analysis.

At the same time, blood was taken to determine platelet aggregation. Then a PCI procedure was performed. Depending on the indications, patients received a metal stent (BMS) or antiproliferative drug-eluting stent (DES). In the case of BMS stent implantation, the patient was reported after 6 months for an outpatient follow-up visit, continuing double antiplatelet therapy (clopidogrel $75 \mathrm{mg} /$ day + ASA $75 \mathrm{mg}$ / day). After implantation of the DES the patient was reporting after 12 months. On the day of the follow-up visit, a blood sample was being taken to determine the concentration of the metabolite of clopidogrel and at the same time, the reactivity of platelets was examined.

\section{Determination of inactive metabolite concentration of clopidogrel}

Few high-performance liquid chromatographic (HPLC) methods for determination of carboxylic acid metabolite of clopidogrel have been reported in the literature [27-29].

A sensitive LC-MS method was also reported for determination of clopidogrel metabolite in plasma, however LC-MS instrument is not yet readily available in all laboratories. The HPLC method with UV detection is the most convenient and common analytical method. The HPLC analysis of inactive metabolite clopidogrel was performed on a chromatograph HP 1100 with UV detector at a wavelength of $225 \mathrm{~nm}$. Chromatographic separation was achieved by a LiChroCart ${ }^{\circledR} 125-4$ LiChrispher $^{\circledR} 100 \mathrm{Rp}-18 \mathrm{e}(5 \mu \mathrm{m})$ column (Merck). The isocratic mobile phase pumped at a flow rate $1 \mathrm{~mL} / \mathrm{min}$ consisted $0.01 \mathrm{M} \mathrm{KH}_{2} \mathrm{PO}_{4}$ and acetonitrile $(70: 30 \mathrm{v} / \mathrm{v})$ adjusted to $\mathrm{pH} 3.0$ by phosphoric acid. All separations were performed at $22{ }^{\circ} \mathrm{C}$ temperature. The carboxylic acid metabolite of clopidogrel was purchased from Pharmaceutical Research Institute (Warsaw, Poland). Piroxicam (PRX, internal standard, IS) was purchased from Sigma-Aldrich.

Stock standard solutions of the carboxylic acid metabolite of clopidogrel and IS were prepared in methanol at $1 \mathrm{mg} / \mathrm{mL}$ concentrations. Then, standard solutions of 4.0 , $10.0,20.0,40.0,60.0,80.0$ and $160.0 \mu \mathrm{g} / \mathrm{mL}$ of carboxylic acid metabolite of clopidogrel and $500 \mu \mathrm{g} / \mathrm{mL}$ IS were prepared also in methanol. The volume of $50 \mu \mathrm{l}$ carboxylic acid metabolite of clopidogrel and $50 \mu \mathrm{IS}$ was transferred to a vial containing $0.9 \mathrm{~mL}$ human blank plasma. The resulting plasma samples contained $0.2,0.5,1.0,2.0,3.0,4.0,8.0 \mu \mathrm{g} /$ $\mathrm{mL}$ carboxylic acid metabolite of clopidogrel. The plasma samples applied on $\mathrm{C}_{18}$ bonded SPE cartridges and absorbed analytes were eluted with $1 \mathrm{~mL}$ of methanol. The organic layer was transferred to a clean test tube and evaporated to dryness at $40{ }^{\circ} \mathrm{C}$ in a water bath under a steam of nitrogen. The residue was reconstituted in $100 \mu \mathrm{l}$ mobile phase and $25 \mu \mathrm{l}$ were injected into the chromatographic system. Designed HPLC method with UV detector was developed and validated for the determination of non-active metabolite of clopidogrel in plasma. The retention times for carboxylic acid metabolite of clopidogrel and IS were 1.9 and $8.9 \mathrm{~min}$ respectively and did not interfere with peaks from any drugs co-administered with clopidogrel. The method was linear in the ranges of $0.2-4.0 \mu \mathrm{g} / \mathrm{mL}$ in plasma for the carboxylic acid metabolite of clopidogrel with a correlation coefficient $\left(r^{2}\right)$ of $99.93-99.99 \%$. Limit of detection (LOD) of the carboxylic acid metabolite of clopidogrel was determined as an $\mathrm{S} / \mathrm{N}$ baseline ratio of 3:1 for plasma samples and it was found to be $0.025 \mu \mathrm{g} / \mathrm{mL}$. The value of the limit of quantitaion (LOQ) in plasma for the carboxylic acid metabolite of clopidogrel was $0.1 \mu \mathrm{g} / \mathrm{mL}$. The intra- and inter-assay precision values were $\leq 5.98 \%$. The intra- and inter-day accuracy of the method was $\leq 3.75 \%$. Recovery of carboxylic acid metabolite of clopidogrel from plasma samples was in a range of $85.76-96.91 \%$.

Simple sample preparation procedure and a short chromatographic run time make this method suitable for rapid and reliable determination of clopidogrel metabolite in plasma.

\section{Pharmacodynamic assay}

The pharmacodynamic response was estimated by an impedance method (Multiplate analyzer; Dynabyte medical, Germany). Samples for the assay platelet aggregation in 155 patients who received $75 \mathrm{mg}$ of clopidogrel and $75 \mathrm{mg}$ of ASA were collected $2 \mathrm{~h}$ after clopidogrel administration into hirudin-coated S Monovette systems (SarstedtAG\&Co., Germany). The ADP-induced platelet aggregation test was performed in accordance with the manufacturer's instruction. Platelet aggregation was quantified as the area under the curve $\left(\mathrm{AUC}_{\mathrm{agr}}\right)$ of the units vs. time (AU.min). According to the consensus opinion of Bonello et al. [30], a cut-off point of $500 \mathrm{AU} \cdot \mathrm{min}$ for platelet aggregation in response to ADP should be used as the threshold for an increased risk of thrombotic events during clopidogrel therapy. Patients with $\mathrm{AUC}_{\mathrm{agr}}$ values $>500 \mathrm{AU} \cdot \mathrm{min}$ could be characterized as "non-responders" for clopidogrel therapy. 


\section{Determination of genetic polymorphisms}

Genomic DNA was extracted from $200 \mu \mathrm{L}$ of whole blood samples using GeneMATRIX Quick Blood DNA Purification Kit (EURx, Poland). Each sample was genotyped for a presence of the most frequent SNPs within $C Y P 2 C 19$ (rs4244285, *2 allele, and rs12248560, *17 allele),CYP3A4 (rs35599367, *22 allele), CYP3A5 (rs776746, *3 allele), $A B C B 1$ (rs $1045642,3435 \mathrm{C}>\mathrm{T}$, rs $2032582,2677 \mathrm{G}>\mathrm{A}, \mathrm{T}$, and rs1128503, 1236T $>\mathrm{C}$ ), and PON1 (rs662, Q192R) genes. Prevalidated allelic discrimination TaqMan real-time PCR assays (Life Technologies, USA) were used for genotype determination. Fluorescence data was captured using an 7500 FAST Real-Time PCR System (Life Technologies, USA), after 40 cycles of PCR.

\section{Statistical analysis}

The statistical analysis was performed using Statistica version 10.0 software. Wilcoxon signed-rank test was used to study differences between quantitative variables measured before and after PCI while McNemar's test was used for paired comparison of qualitative variables. The Mann-Whitney's $U$ test was applied to evaluate the influence of genotypes on the concentration of carboxylic acid metabolite of clopidogrel and pharmacodynamic response before and after PCI. Correlations between the concentration of inactive metabolite and platelet aggregation were calculated with the Spearman correlation coefficient (Rs). A general linear model (GLM) was used for multivariate analysis, where dependent variables were normalized by logarithmic transformation. A $p$ value of $<0.05$ was considered significant.

\section{Results}

\section{Patient characteristics}

Demographic characteristics, clinical information of the patients are shown in Table 1.

\section{Concentrations of the inactive metabolite of clopidogrel and platelet aggregation in patients before and after $\mathrm{PCI}$}

The concentrations of the inactive metabolite of clopidogrel and platelet aggregation are presented in Table 2. The plasma concentration of inactive metabolite of clopidogrel in 155 patients in a sample taken $2 \mathrm{~h}$ after double antiplatelet therapy before PCI, varied substantially among patients from 0.04 to $5.73 \mu \mathrm{g} / \mathrm{mL}$ (mean 1.20). After stent implantation, only 100 patients completed the study, respectively

Table 1 Patients demographics and patients characteristics

\begin{tabular}{|c|c|c|}
\hline Characteristic & Female $n=45($ mean \pm SD $)$ & $\begin{array}{l}\text { Male } n=110 \\
(\text { mean } \pm \text { SD) }\end{array}$ \\
\hline Age (years) & $63.36 \pm 9.09$ & $61.65 \pm 8.17$ \\
\hline Height $(\mathrm{cm})$ & $158.49 \pm 5.65$ & $173.15 \pm 5.72$ \\
\hline Body weight (kg) & $69.52 \pm 14.00$ & $84.48 \pm 12.18$ \\
\hline \multirow[t]{2}{*}{ BMI } & $27.20 \pm 5.48$ & $28.12 \pm 3.33$ \\
\hline & & $\begin{array}{l}n-\text { Total num- } \\
\text { ber of patients }\end{array}$ \\
\hline Clopidogrel $75 \mathrm{mg}$ & & 155 \\
\hline Acid acetylsalicylic $75 \mathrm{mg}$ & & 155 \\
\hline Simvastatin & & 14 \\
\hline Rosuvastatin & & 36 \\
\hline Atorvastatin & & 97 \\
\hline Omeprazol & & 6 \\
\hline Pantoprazol & & 90 \\
\hline Angiotensin-converting enzyme inhibitor & & 128 \\
\hline Angiotensin receptor blocker & & 13 \\
\hline Calcium channel blocker & & 13 \\
\hline Beta blocker & & 147 \\
\hline Diuretic & & 47 \\
\hline Diabetes mellitus & & 44 \\
\hline Hyperlipidaemia & & 105 \\
\hline Smoking & & 53 \\
\hline
\end{tabular}


Table 2 Concentrations of the inactive metabolite of clopidogrel (C) and platelet aggregation $\left(\mathrm{AUC}_{\mathrm{agr}}\right)$ in patients before and after PCI

\begin{tabular}{llll}
\hline Parameter & Before PCI $n=155$ & $\begin{array}{l}\text { After } \\
6 \text { months } n=73\end{array}$ & $\begin{array}{l}\text { PCI } \\
12 \text { months } n=27\end{array}$ \\
\hline $\begin{array}{l}\mathrm{C} \pm \mathrm{SD}(\mu \mathrm{g} / \\
\mathrm{mL})(\mathrm{min}-\end{array}$ & $1.20 \pm 0.89(0.04-5.73)$ & $1.15 \pm 0.66(0.17-3.24)$ & $1.10 \pm 0.35(0.36-1.67)$ \\
$\quad \mathrm{max})$ & & \\
$\begin{array}{l}\mathrm{AUC} \\
\quad(\mathrm{AUr}+\mathrm{min}) \\
(\mathrm{min}-\mathrm{SD})\end{array}$ & $305.75 \pm 191.42(42-1275)$ & $309.66 \pm 176.23(51-1108)$ & $305.67 \pm 252.72(55-1137)$ \\
\hline
\end{tabular}

73 patients with metal stent (BMS) after 6 months and 27 patients with antiproliferative drug-eluting stent (DES) after 12 months. After PCI the plasma concentration of inactive metabolite of clopidogrel were $1.15(0.17-3.24) \mu \mathrm{g} / \mathrm{mL}$ and $1.10(0.36-1.67) \mu \mathrm{g} / \mathrm{mL}$ after BMS and DES stents, respectively. The results of the Wilcoxon signed-rank test showed that the plasma concentration of inactive metabolite of clopidogrel before and after PCI were not significantly different ( $p=0.86$ and 0.36 for BMS and DES stents, respectively).

The inter-subject variability in platelet reactivity was observed before and after PCI. The results of platelet tests performed $2 \mathrm{~h}$ after double antiplatelet therapy were 305.75 (42-1275) AU.min before PCI, and 309.66 (59-1108) and 305.67 (55-1137) AU.min after BMS and DES stents, respectively. Platelet aggregation before PCI was not statistically significantly different from the value after PCI ( $p=0.96$ and 0.87 for BMS and DES stents, respectively). Taking into account a cut-off point of $500 \mathrm{AU} \cdot \mathrm{min}$ for platelet aggregation in response to ADP as the threshold for "responders" and "non-responders" to the clopidogrel therapy, the increased numbers of "responders" were observed after stent implantation and double antiplatelet therapy. Among 155 patients, before stent implantation, 23 (14.8\%) could be characterized as "non-responders" with $\mathrm{AUC}_{\text {agr }}$ values $>500$ AU.min, while platelet aggregation in 132 (85.2\%) patients exhibited AUC values $\leq 500 \mathrm{AU} \cdot \mathrm{min}$. These patients were classified as "responders" to clopidogrel therapy. After stent implantation and antiplatelet maintenance therapy (100 analyzed patients) the proportion of patients with high reactivity of $\mathrm{AUC}_{\text {agr }}$ values $>500 \mathrm{AU} \cdot \min$ was $12 \%$ and the number of patients with $\mathrm{AUC}_{\mathrm{agr}}$ values $\leq 500 \mathrm{AU} \cdot \min$ was $88 \%$. However, no statistically significant differences between the results before and after PCI were observed ( $p=0.80, \mathrm{McNe}$ mar's test).

No statistically significant correlations were found between the inactive metabolite concentration of clopidogrel and aggregation tests before and after PCI (Spearman's rank correlation coefficients: $\mathrm{Rs}=-0.04, p=0.61$, and $\mathrm{Rs}=-0.05, p=0.61$, respectively).

\section{Effect of genetic polymorphisms on the inactive metabolite concentration of clopidogrel and platelet aggregation in patients before and after $\mathrm{PCl}$}

Genotype distribution of all investigated SNPs was in Hardy-Weinberg equilibrium. Table 3 shows the association of CYP2C19 genotypes with clopidogrel metabolite concentration and platelet aggregation in patients before and after PCI. Patients with $* 1 / * 1, * 1 / * 17$ and $* 17 / * 17$ of $C Y P 2 C 19$ genotypes were classified as extensive metabolizers (EM). Participants with $* 1 / * 2$ and $* 2 / * 17$ of CYP2C 19 genotypes were classified as intermediate metabolizers (IM). There was no one with a $* 2 / * 2$ genotype. Among 155 patients 115 (74.2\%) were EM and 40 (25.8\%) IM. In the 100 patients who completed the study after PCI, there were $70(70 \%)$
Table 3 Clopidogrel inactive metabolite concentration and platelet aggregation in patients with $C Y P 2 C 19$ genotype before and after PCI

\begin{tabular}{|c|c|c|c|}
\hline \multirow[t]{2}{*}{ Parameter } & \multicolumn{2}{|l|}{ Genotype $C Y P 2 C 19$} & \multirow{2}{*}{$\begin{array}{l}p \text { (Mann- } \\
\text { Whitney } U \\
\text { test) }\end{array}$} \\
\hline & $* 1 / * 1+* 1 / * 17+* 17 / * 17(\mathrm{EM})$ & $* 1 / * 2+* 2 / * 17(\mathrm{IM})$ & \\
\hline Before PCI & $N=115(74.2 \%)$ & $N=40(25.8 \%)$ & \\
\hline $\mathrm{C}(\mu \mathrm{g} / \mathrm{mL})$ & $1.18 \pm 0.78(0.06-5.74)$ & $1.25 \pm 1.19(0.07-6.66)$ & NS \\
\hline $\mathrm{AUC}_{\mathrm{agr}}(\mathrm{AU} \cdot \mathrm{min})$ & $289.26 \pm 180.65(42-1275)$ & $353.15 \pm 214.89(110-1275)$ & 0.018 \\
\hline After PCI & $N=70(70 \%)$ & $N=30(30 \%)$ & \\
\hline $\mathrm{C}(\mu \mathrm{g} / \mathrm{mL})$ & $1.17 \pm 0.62(0.05-3.24)$ & $1.05 \pm 0.53(0.05-2.78)$ & NS \\
\hline $\mathrm{AUC}_{\mathrm{agr}}(\mathrm{AU} \cdot \mathrm{min})$ & $262.60 \pm 146.38(51-1137)$ & $415.87 \pm 257.67(82-1137)$ & 0.0006 \\
\hline
\end{tabular}

$n$ number of patients, $N S$ not statistically significant $p>0.05$

$\mathrm{AUC}_{\mathrm{agr}}$ - platelet aggregation; $\mathrm{C}$-clopidogrel inactive metabolite concentration

Mean \pm SD and (Min-Max) values are presented 
EM and $30(30 \%)$ IM. The concentration of the inactive metabolite of clopidogrel was not significantly different in the intermediate metabolizers compared with the group of extensive metabolizers both before and after PCI.

Inhibition of platelet aggregation (AUCagr) was found to be significantly better in EM than in IM, before $(p<0.018)$ as well as after $(p<0.0006)$ PCI. Despite the fact that in the IM group there were 15 patients with genotype $* 2 / * 17$.

Tables 4 and 5 show the association of CYP3A4 and CYP3A5 genotypes with clopidogrel metabolite concentration and platelet aggregation in patients before and after PCI. In the studied group, there were no significant differences of inactive metabolite concentration of clopidogrel and platelet aggregation between patients with $C Y P 3 A 4$ and $C Y P 3 A 5$ genotypes.

Tables 6, 7 and 8 show the association of $A B C B 1$ $3435 C>T, 2677 C>T$ and $1236 C>T$ genotypes with clopidogrel metabolite concentration and platelet aggregation in patients before and after PCI. There were no significant differences in the concentrations of the metabolite of clopidogrel and platelet aggregation in the studied patients with individual genotypes of $A B C B 13435 \mathrm{C}>\mathrm{T}$ and $A B C B 1$ $1236 \mathrm{C}>\mathrm{T}$ polymorphisms. The presence of the A allele at position 2677 in the $A B C B 1$ gene was associated with a significantly lower concentration of the metabolite of clopidogrel $(p=0.026)$ before PCI when carriers and non-carriers of the A allele were compared. This difference was not observed after stent implantation, but it should be noted that the statistical power for this comparison is very small due to the small number of patients with the A allele examined after PCI $(n=2)$.

Table 9 shows the association of PON1192QR genotype with clopidogrel metabolite concentration and platelet aggregation in patients before and after PCI. There were no significant differences between the inactive metabolite concentration of clopidogrel and platelet aggregation in patients with the examined genotype.

\section{Multivariate analysis}

Multivariate analysis (GLM) including age, gender, BMI, and $C Y P 2 C 19 * 2$ genotype as independent variables and logarithm of platelet aggregation as dependent variable showed that presence of CYP2C19*2 allele is an independent factor associated with significantly higher platelet aggregation in study group both before PCI $(\beta=+0.18, p=0.019)$ and after
Table 4 Clopidogrel metabolite concentration $(\mu \mathrm{g} / \mathrm{mL})$ and platelet aggregation $(\mathrm{AU} \cdot \mathrm{min})$ in patients with genotype CYP3A4 before and after PCI
Table 5 Clopidogrel metabolite concentration $(\mu \mathrm{g} / \mathrm{mL})$ and platelet aggregation (AU.min) in patients with genotype CYP3A5 before and after PCI

\begin{tabular}{llll}
\hline Parameter & Genotype CYP3A4 & \multirow{2}{*}{$\begin{array}{c}p \text { Mann- } \\
\text { Whitney } U \\
\text { test })\end{array}$} \\
\cline { 2 - 3 } & $* 1 / * 1$ & $* 1 / * 22$ & \\
\hline Before PCI & $n=149(96.1 \%)$ & $n=6(3.9 \%)$ & $\mathrm{NS}$ \\
$\mathrm{C}(\mu \mathrm{g} / \mathrm{mL})$ & $1.15 \pm 0.76(0.04-3.78)$ & $2.44 \pm 2.33(0.77-6.66)$ & $\mathrm{NS}$ \\
$\mathrm{AUC}_{\mathrm{agr}}(\mathrm{AU} \cdot \mathrm{min})$ & $298.93 \pm 173.01(42-946)$ & $475.00 \pm 454.63(61-1275)$ & \\
After PCI & $n=97(97 \%)$ & $n=3(3 \%)$ & $\mathrm{NS}$ \\
$\mathrm{C}(\mu \mathrm{g} / \mathrm{mL})$ & $1.13 \pm 0.60(3.12-3.24)$ & $1.32 \pm 0.48(0.97-1,86)$ & $\mathrm{NS}$ \\
$\mathrm{AUC}_{\text {agr }}(\mathrm{AU} \cdot \min )$ & $304.17 \pm 191.71(51-1137)$ & $451.33 \pm 391.05(64-846)$ & \\
\hline
\end{tabular}

$n$ number of patients, $N S$ not statistically significant $p>0.05$

$\mathrm{AUC}_{\mathrm{agr}}$ - platelet aggregation (AU.min); C—clopidogrel metabolite concentration $(\mu \mathrm{g} / \mathrm{mL})$

Mean \pm SD and (Min-Max) values are presented

\begin{tabular}{|c|c|c|c|}
\hline \multirow[t]{2}{*}{ Parameter } & \multicolumn{2}{|l|}{ Genotype $C Y P 3 A 5$} & \multirow{2}{*}{$\begin{array}{l}p \text { (Mann- } \\
\text { Whitney } U \\
\text { test) }\end{array}$} \\
\hline & $* 1 / * 1+* 1 / * 3$ & $* 3 / * 3$ & \\
\hline Before PCI & $n=15(9.7 \%)$ & $n=140(90.3 \%)$ & \\
\hline $\mathrm{C}(\mu \mathrm{g} / \mathrm{mL})$ & $1.04 \pm 0.87(0.07-3.53)$ & $1.21 \pm 0.90(0.04-6.66)$ & NS \\
\hline $\mathrm{AUC}_{\mathrm{agr}}(\mathrm{AU} \cdot \min )$ & $340.67 \pm 190.65(131-743)$ & $302.01 \pm 191.80(42-1275)$ & NS \\
\hline After PCI & $n=12(12 \%)$ & $n=88(88 \%)$ & \\
\hline $\mathrm{C}(\mu \mathrm{g} / \mathrm{mL})$ & $1.07 \pm 0.48(0.20-1.92)$ & $1.14 \pm 0.61(3.12-3.24)$ & NS \\
\hline $\mathrm{AUC}_{\mathrm{agr}}(\mathrm{AU} \cdot \mathrm{min})$ & $391.17 \pm 307.15(105-1137)$ & $297.32 \pm 178.32(51-1108)$ & NS \\
\hline
\end{tabular}

$n$ number of patients, $N S$ not statistically significant $p>0.05$

$\mathrm{AUC}_{\mathrm{agr}}$ - platelet aggregation (AU.min); C-clopidogrel metabolite concentration $(\mu \mathrm{g} / \mathrm{mL}$ )

Mean \pm SD and (Min-Max) values are presented 
Table 6 Clopidogrel metabolite concentration $(\mu \mathrm{g} / \mathrm{mL})$ and platelet aggregation (AU.min) in patients with genotype $A B C B 13435 C>T$ before and after $\mathrm{PCl}$

\begin{tabular}{|c|c|c|c|}
\hline \multirow[t]{2}{*}{ Parameter } & \multicolumn{3}{|c|}{ Genotype $A B C B 13435 C>T$} \\
\hline & $\mathrm{CC}$ & $\mathrm{CT}$ & TT \\
\hline Before PCI & $N=40(25.8 \%)$ & $n=72(46.5 \%)$ & $n=43(27.7 \%)$ \\
\hline $\mathrm{C}(\mu \mathrm{g} / \mathrm{mL})$ & $1.13 \pm 0.75(0.08-5.14)$ & $\begin{array}{l}1.32 \pm 1.07(0.06-6.66) \\
\text { NS }\end{array}$ & $\begin{array}{l}1.05 \pm 0.65(0.08-3.12) \\
\text { NS }\end{array}$ \\
\hline $\mathrm{AUC}_{\mathrm{agr}}(\mathrm{AU} \cdot \min )$ & $287.00 \pm 152.57(82-635)$ & $\begin{array}{l}319.86 \pm 215.18(42-1275) \\
\text { NS }\end{array}$ & $\begin{array}{l}299.56 \pm 183.68(61-946) \\
\text { NS }\end{array}$ \\
\hline After PCI & $n=24(24 \%)$ & $N=46(46 \%)$ & $N=30(30 \%)$ \\
\hline $\mathrm{C}(\mu \mathrm{g} / \mathrm{mL})$ & $1.10 \pm 0.52(0.20-1.92)$ & $\begin{array}{l}1.18 \pm 0.67(0.11-3.24) \\
\text { NS }\end{array}$ & $\begin{array}{l}1.12 \pm 0.58(3.12-2.44) \\
\text { NS }\end{array}$ \\
\hline $\mathrm{AUC}_{\mathrm{agr}}(\mathrm{AU} \cdot \min )$ & $300.64 \pm 178.05(99-899)$ & $\begin{array}{l}313.24 \pm 200.92(55-1137) \\
\text { NS }\end{array}$ & $\begin{array}{l}279.93 \pm 220.14(51-1108) \\
\text { NS }\end{array}$ \\
\hline
\end{tabular}

$n$ number of patients, $N S$ not statistically significant when compared to CC genotype, $p>0.05$ (MannWhitney $U$ test)

$\mathrm{AUC}_{\mathrm{agr}}$ - platelet aggregation (AU.min); C—clopidogrel metabolite concentration $(\mu \mathrm{g} / \mathrm{mL}$ )

Mean \pm SD and (Min-Max) values are presented

Table 7 Clopidogrel metabolite concentration $(\mu \mathrm{g} / \mathrm{mL})$ and platelet aggregation (AU.min) in patients with genotype $A B C B 12677 G>T, A$ before and after PCI

\begin{tabular}{|c|c|c|c|c|}
\hline \multirow[t]{2}{*}{ Parameter } & \multicolumn{4}{|c|}{ Genotype $A B C B 12677 G>T, A$} \\
\hline & GG & GT & TT & $\mathrm{GA}+\mathrm{TA}$ \\
\hline Before PCI & $n=55(35.5 \%)$ & $n=64(41.3 \%)$ & $n=30(19.3 \%)$ & $n=6(3.9 \%)$ \\
\hline $\mathrm{C}(\mu \mathrm{g} / \mathrm{mL})$ & $1.12 \pm 0.72(0.08-3.74)$ & $\begin{array}{l}1.31 \pm 1.10(0.07-6.66) \\
\text { NS }\end{array}$ & $\begin{array}{l}1.21 \pm 0.69(0.06-3.12) \\
\text { NS }\end{array}$ & $\begin{array}{l}0.57 \pm 0.42(0.09-1.27) \\
p=0.026^{*}\end{array}$ \\
\hline AUCagr (AU·min) & $308.00 \pm 171.56(82-855)$ & $\begin{array}{l}338.12 \pm 234.45(42-1275) \\
\text { NS }\end{array}$ & $\begin{array}{l}246.66 \pm 106.35(61-514) \\
\text { NS }\end{array}$ & $\begin{array}{l}235.17 \pm 109.63(118-410) \\
\text { NS* }\end{array}$ \\
\hline After PCI & $n=37(37 \%)$ & $n=38(38 \%)$ & $n=23(23 \%)$ & $n=2(2 \%)$ \\
\hline $\mathrm{C}(\mu \mathrm{g} / \mathrm{mL})$ & $1.11 \pm 0.62(0.11-3.23)$ & $\begin{array}{l}1.13 \pm 0.61(3.12-3.24) \\
\text { NS }\end{array}$ & $\begin{array}{l}1.17 \pm 0.56(0.57-2.44) \\
\text { NS }\end{array}$ & $\begin{array}{l}1.40 \pm 0.04(1.37-1.43) \\
p=\mathrm{NS}^{*}\end{array}$ \\
\hline AUCagr (AU·min) & $328.49 \pm 176.41(64-899)$ & $\begin{array}{l}335.21 \pm 246.70(55-1137) \\
\text { NS }\end{array}$ & $\begin{array}{l}235.30 \pm 127.15(51-531) \\
\text { NS }\end{array}$ & $\begin{array}{l}277.00 \pm 46.67(244-310) \\
\text { NS* }\end{array}$ \\
\hline
\end{tabular}

$n$ number of patients, $N S$ not statistically significant when compared to GG genotype, $p>0.05$ (Mann-Whitney $U$ test)

$\mathrm{AUC}_{\mathrm{agr}}$-platelet aggregation (AU.min); C—clopidogrel metabolite concentration $(\mu \mathrm{g} / \mathrm{mL})$

Mean \pm SD and (Min-Max) values are presented

*For carriers of 2677A allele (GA and TA genotypes) compared to non-carriers of A allele (GG + GT + TT genotypes)

PCI $(\beta=+0.32, p=0.0022)$. In this model older age is an independent factor associated with higher platelet aggregation before PCI $(\beta=+0.23, p=0.0032)$. Analogical analysis with the logarithm of clopidogrel metabolite concentration as dependent variable showed that the presence of A allele in 2677 position in $A B C B 1$ gene is an independent factor associated with significantly lower clopidogrel metabolite concentration before PCI $(\beta=-0.18, p=0.022)$. In that model male gender is an independent factor associated with significantly lower clopidogrel metabolite concentration $(\beta=-0.22, p=0.0049)$.

\section{Discussion}

Dual antiplatelet therapy with aspirin and P2Y12 inhibitor is recommended for ischemic events after acute coronary syndromes [1-4]. As a potent P2Y12 inhibitor ticagrelol is strongly recommended over clopidogrel to reduce the risk of ischemic recurrences [3]. However, the effective ischemic protection offered by ticagrelol is potentially counterbalanced by an increased risk of bleeding [3, 4]. Recently, increased attention has been focused on preventing bleeding complications in patients on dual antiplatelet therapy, based on evidence showing that risk of death after major bleeding is equal, if not higher than, that following myocardial infarction $[4,5]$. Several registries have shown that clopidogrel 
Table 8 Clopidogrel metabolite concentration $(\mu \mathrm{g} / \mathrm{mL})$ and platelet aggregation (AU.min) in patients with genotype $A B C B 11236 C>T$ before and after $\mathrm{PCl}$

\begin{tabular}{llll}
\hline Parameter & \multicolumn{2}{l}{ Genotype $A B C B 11236 C>T$} & \\
\cline { 2 - 4 } & $\mathrm{CC}$ & $\mathrm{CT}$ & $\mathrm{TT}$ \\
\hline Before PCI & $n=56(36.1 \%)$ & $n=67(43.2 \%)$ & $n=32(20.7 \%)$ \\
$\mathrm{C}(\mu \mathrm{g} / \mathrm{mL})$ & $1.09 \pm 0.72(0.07-5.14)$ & $1.30 \pm 1.08(0.07-6.66)$ & $1.17 \pm 0.69(0.06-3.12)$ \\
& & $\mathrm{NS}$ & $\mathrm{NS}$ \\
$\mathrm{AUC}_{\mathrm{agr}}(\mathrm{AU} \cdot \mathrm{min})$ & $288.40 \pm 165.42(82-855)$ & $343.18 \pm 229.22(42-1275)$ & $257.75 \pm 125.11(61-635)$ \\
& & $\mathrm{NS}$ & $\mathrm{NS}$ \\
$\mathrm{After} \mathrm{PCI}$ & $n=36(36 \%)$ & $n=41(41 \%)$ & $n=23(23 \%)$ \\
$\mathrm{C}(\mu \mathrm{g} / \mathrm{mL})$ & $1.17 \pm 0.62(0.11-3.23)$ & $1.07 \pm 0.59(0.05-3.24)$ & $1.20 \pm 0.57(0.57-2.44)$ \\
& & $\mathrm{NS}$ & $\mathrm{NS}$ \\
$\mathrm{AUC}_{\mathrm{agr}}(\mathrm{AU} \cdot \mathrm{min})$ & $330.81 \pm 174.82(64-899)$ & $329.00 \pm 241.45(55-1137)$ & $237.40 \pm 125.07(51-531)$ \\
& & $\mathrm{NS}$ & $\mathrm{NS}$ \\
\hline
\end{tabular}

$n$ number of patients, NS not statistically significant when compared to CC genotype, $p>0.05$ (MannWhitney $U$ test)

$\mathrm{AUC}_{\mathrm{agr}}$ - platelet aggregation (AU.min); C—clopidogrel metabolite concentration $(\mu \mathrm{g} / \mathrm{mL})$

Mean \pm SD and (Min-Max) values are presented

\begin{tabular}{llll}
\hline Parameter & \multicolumn{2}{l}{ Genotype PON1 192QR $(A>G)$} & \\
\cline { 2 - 3 } & QQ & QR & RR \\
\hline Before PCI & $n=83(53.5 \%)$ & $n=60(38.7 \%)$ & $n=12(7.8 \%)$ \\
$\mathrm{C}(\mu \mathrm{g} / \mathrm{mL})$ & $1.26 \pm 0.77(0.04-3.74)$ & $1.13 \pm 1.05(0.06-6.66)$ & $1.08 \pm 0.81(0.47-3.28)$ \\
& & $\mathrm{NS}$ & $\mathrm{NS}$ \\
$\mathrm{AUC}_{\mathrm{agr}}(\mathrm{AU} \cdot \mathrm{min})$ & $297.45 \pm 172.90(49-855)$ & $317.33 \pm 211.15(92-1275)$ & $305.25 \pm 223.02(42-820)$ \\
& & $\mathrm{NS}$ & $\mathrm{NS}$ \\
$\mathrm{After} \mathrm{PCI}$ & $n=51(51 \%)$ & $n=42(42 \%)$ & $n=7(7 \%)$ \\
$\mathrm{C}(\mu \mathrm{g} / \mathrm{mL})$ & $1.11 \pm 0.65(0.05-3.24)$ & $1.17 \pm 0.50(0.02-2.44)$ & $1.10 \pm 0.80(0.55-2.78)$ \\
& & $\mathrm{NS}$ & $\mathrm{NS}$ \\
$\mathrm{AUC}_{\mathrm{agr}}(\mathrm{AU} \cdot \mathrm{min})$ & $308.12 \pm 177.46(51-899)$ & $299.79 \pm 225.83(55-1137)$ & $364.71 \pm 185.45(153-664)$ \\
& & $\mathrm{NS}$ & $\mathrm{NS}$ \\
\hline
\end{tabular}

$n$ number of patients, NS not statistically significant when compared to QQ genotype, $p>0.05$ (MannWhitney $U$ test)

$\mathrm{AUC}_{\text {agr }}$ - platelet aggregation; $\mathrm{C}$-clopidogrel metabolite concentration

Mean \pm SD and (Min-Max) values are presented is frequently preferred by clinicians in patients with acute coronary syndrome $[4,6,7,9]$. Sub-analysis of the STARTANTIPLATELET registry [4] confirms that clopidogrel, rather than potent P2Y12 inhibitors, is frequently used in real-world practice, especially in acute coronary syndrome patients with high ischemic and bleeding risk. No difference for ischemic and bleeding events was observed in highbleeding risk patients on clopidogrel versus ticagrelol [4]. Gimbel et al. [31] investigated the safety and efficacy of clopidogrel compared with ticagrelor or prasugrel in older patients with non-ST-elevation acute coronary syndrome (NSTE-ACS). They showed that clopidogrel is an important therapeutic agent for both primary and secondary prevention of coronary heart disease and could be an alternative P2Y12 inhibitor especially for elderly patients with higher bleeding risk.
Despite a large number of studies regarding cardiovascular events in clopidogrel treatment patients, great effort is put to explain the mechanism of treatment resistance and the specificity and sensitivity of the markers helpful in therapy individualization. The active metabolite of clopidogrel is a very labile molecule that degrades rapidly in blood after sample collection, therefore determination of the concentration of the inactive carboxylic acid metabolite of clopidogrel might be useful to evaluate the response to clopidogrel therapy. Serebruany et al. [26] showed that the plasma level of inactive carboxylic acid metabolite of clopidogrel is a useful marker for monitoring compliance to clopidogrel.

Antiplatelet response to clopidogrel and its influence upon the risk of cardiovascular adverse events among patients with stable coronary artery disease undergoing percutaneous coronary intervention (PCI) has been investigated in the same groups of patients from the Department 
of Cardiology by Olędzki et al. [32]. It has been shown that platelet response to clopidogrel has no impact upon postprocedural adverse events at mid-term follow-up in patients with stable CAD undergoing PCI. This finding suggests that routine platelet reactivity testing is not beneficial in this group of patients.

The aim of the study was to investigate whether the so far studied polymorphisms of genes involved in the metabolism of clopidogrel and its absorption may affect the concentration of the inactive carboxyl metabolite which could be a potential marker for monitoring compliance to clopidogrel. The active thiol metabolite of clopidogrel is unstable in plasma. Its maximum concentration varies between 7.1-13.3 ng/mL. Due to its short half-life, the determination of the concentration of this compound requires specific and sensitive analytical methods. Evaluation of the pharmacokinetics of clopidogrel and its metabolites requires the collection of at least several blood samples. In the clinical setting, it is very difficult. In contrast, the inactive metabolite of clopidogrel occurs in concentrations greater than 1000-fold higher and is present significantly longer in plasma.

The paper presents a study of the influence of selected polymorphisms CYP2C19, CYP 3A4/5, ABCB1 and PON1 on the concentration of inactive metabolite clopidogrel and its pharmacodynamic effect evaluated by platelet aggregation in patients before and after PCI treated clopidogrel with ASA. For this purpose, a simple and reproducible HPLC method with UV detection for the determination of clopidogrel metabolite in human plasma was developed and validated. For HPLC analysis with UV detection a small amount of plasma was used, a reduced amount of acetonitrile relative to the phosphate buffer in the mobile phase. Under the chromatographic conditions described, the drug and I.S. were well resolved in plasma samples and eluted at $1.9 \mathrm{~min}$ and 8.9 min, respectively. In the developed method, the retention time of clopidogrel metabolite and I.S. was comparable with the retention time of the inactive clopidogrel metabolite obtained in the method developed by Rouini et al. [33] and Mitakos et al. [34]. However, in the methods developed by Souri et al. [35] and Singh et al. [36] the elution times were significantly longer. The developed method was used to determine concentrations of inactive clopidogrel metabolite measured at steady state in 155 patients qualified for PCI. The time of sampling was determined based on the pharmacokinetic studies conducted so far. It was the time of the peak concentration of both clopidogrel and its active metabolite [28, 36, 37]. In the clinical setting, it was not possible to take more blood samples from the examined patients. The concentration of the inactive metabolite of clopidogrel determined $2 \mathrm{~h}$ after administration drug was individually variable and was $0.04 \mu \mathrm{g} / \mathrm{mL}$ to $5.73 \mu \mathrm{g} / \mathrm{mL}$ on average $1.20 \mu \mathrm{g} / \mathrm{mL}$. Large differences in the carboxylic acid concentrations of clopidogrel demonstrated in our studies were also observed and reported in other authors' reports. The results obtained were comparable to the values of maximum concentrations of inactive metabolite obtained in the Caucasian population $[33,37]$. In conclusion, our HPLC method is a simple, specific, reproducible with low-cost determination of non-active metabolite of clopidogrel in plasma of clopidogrel treatment patients. The non-active metabolite of clopidogrel measured in a steady state in a single blood sample is a good marker for drug usage.

One of the most frequently performed analyzes is the influence of CYP2C19 genotypes on the pharmacodynamic effect of clopidogrel. It has been shown that CYP2C19*2 variant was associated with poor clopidogrel response and increase ischemic events. However, it has also been confirmed that CYP2C19*17 polymorphism may lead to a higher concentration of clopidogrel active metabolite, an enhanced antiplatelet activity, and an increased risk of bleeding events during clopidogrel therapy $[10,15,17,18]$. In our study, 40 patients were carriers of the CYP2C19*2 allele. None of the subjects had a homozygous genotype $* 2 / 22$ and there was no CYP2C19*3 allele carrier. In patients with CYP2C19*2 allele significantly reduced anti-aggregation effect after drug administration was observed. The incidence of at least one CYP2C19*2 and CYP2C19*3 allele responsible for disturbed metabolism of clopidogrel in the Caucasian population is estimated at $5-30 \%$ for CYP2C19*2 and less than $1 \%$ for CYP2C19*3 [10, 38, 39]. In studied group 115 subjects were fast metabolizers $(\mathrm{EM})$ with $* 1 / * 1$, $* 1 / * 17, * 17 / * 17$ genotypes and 40 subjects were intermediate metabolizers (IM) with $* 1 / * 2$ and $* 2 / * 17$ genotypes. In EM group platelet aggregation was reduced by $58 \%$ in comparison to values obtained in IM group $(p=0.0006)$. The concentrations of inactive metabolite were not significantly increased in IM compared to EM group which could suggest that less of the drug was metabolized to the active metabolite. This suggestion may be confirmed by a decreased antiplatelet effect of clopidogrel in this group. $\mathrm{Li}$ et al. [40] showed that in subjects with ultrafast metabolism which is associated with $* 17 / * 17$ genotype and in subjects with at least one $* 17$ allele recurrent cardiovascular events were less frequently observed, but the bleeding was more frequent during the use of clopidogrel treatment. This effect of the study has been confirmed by other authors $[15,39]$. In our study 44 subjects were $* 1 / * 17$ allele carriers, 18 subjects had $* 17 / * 17$ genotype and 15 patients $* 2 / * 17$ genotype. In studied group, no significant differences regarding to the effect of CYP2C19*17 alleles on the concentration of inactive metabolite and pharmacodynamic effect of clopidogrel in EM $(1 * / * 17$ and $17 * / * 17)$, whereas in carriers of $* 2 / * 17$ and $* 1 / * 2$ (IM) genotypes the platelet aggregation was significantly higher. Sibbing et al. [15] suggest that in the haplotype $* 2 / * 17$, where one allele encodes the impaired 
enzyme activity and the other allele is responsible for ultrafast metabolism, decreased CYP2C19 activity due to the presence of the CYP2C19 $* 2$ variant is dominant.

It has been shown that clopidogrel absorption is limited by the intestinal efflux transporter P-glycoprotein encoded by $A B C B 1$ gene. Several trials have shown that $A B C B 13435 \mathrm{~T}$ was associated with lower levels of plasma clopidogrel and its active metabolite $[10,23,41,42]$. However, there are also inconsistent reports on the association of $\mathrm{ABCB} 1$ polymorphism and clopidogrel response. We analyzed $3435 \mathrm{C}>\mathrm{T}$, $2677 \mathrm{G}>\mathrm{T}$, A and $1236 \mathrm{C}>\mathrm{T} A B C B 1$ gene polymorphisms. Similarly to other authors, we did not find any association between $C Y P 3 A 4 * 22, C Y P 3 A 5 * 3, A B C B 13435 \mathrm{C}>\mathrm{T}$ and $1236 \mathrm{C}>\mathrm{T}$ and $P O N 1$ 192QR and concentration of inactive clopidogrel metabolite or platelet aggregation in patients before and after PCI $[22,38,42-45]$. We conclude that plasma inactive metabolite concentration and platelet reactivity depend mainly on the CYP2C19 polymorphism.

The determination of the concentration of the inactive metabolite simultaneously with platelet aggregation could be used in clinical practice in patients chronically treated with clopidogrel especially in acute coronary syndrome patients with high ischemic and bleeding risk or in patients with no treatment effect.

Acknowledgements Open access publishing of this article was funded by the Ministry of Science and Higher Education under the agreement No. 879/P-DUN/2019.

Author contributions All authors have contributed significantly to the work and have read and approved the manuscript for publication. B. G.Sz. conceptualized and designed the study, U. A.G. and A. Cz. were responsible for data collection and analysis. Sz. O. were responsible for patient recruitment. M.K. were responsible for analysis of genetic polymorphism. K.S provided statistical expertise and participated in the critical revision of the manuscript. M. J was responsible for data collection and analysis of platelet aggregation. B. G.Sz., U. A.G and A. $\mathrm{Cz}$. contributed to the manuscript writing and discussion.

\section{Compliance with ethical standards}

Conflict of interest All authors declare that they do not have a conflict of interest.

Open Access This article is licensed under a Creative Commons Attribution 4.0 International License, which permits use, sharing, adaptation, distribution and reproduction in any medium or format, as long as you give appropriate credit to the original author(s) and the source, provide a link to the Creative Commons licence, and indicate if changes were made. The images or other third party material in this article are included in the article's Creative Commons licence, unless indicated otherwise in a credit line to the material. If material is not included in the article's Creative Commons licence and your intended use is not permitted by statutory regulation or exceeds the permitted use, you will need to obtain permission directly from the copyright holder. To view a copy of this licence, visit http://creativecommons.org/licenses/by/4.0/.

\section{References}

1. Valgimigli M, Bueno H, Byrne RA, Collet JP, Costa F, Jeppsson A, et al. 2017 ESC focused update on dual antiplatelet therapy in coronary artery disease developed in collaboration with EACTS. Eur J Cardiothorac Surg. 2018;53:34-78.

2. Neumann F-J, Sousa-Uva M, Ahlsson A, Alfonso F, Banning AP, Benedetto U, et al. 2018 ESC/EACTS Guidelines on mycocardial revascularization. Eur Heart J. 2019;40:87-165.

3. Crisci M, Gragnano F, Di Maio M, Diana V, Moscarella E, Pariggiano I, et al. Improving adherence to ticagrelol in patients after acute coronary syndrome: results from the PROGRESS trial. Curr Vasc Pharmacol. 2020;18:294-301.

4. Gragnano F, Moscarella E, Calabro P, Cesaro A, Pafundi PC, Ielasi A, et al. Clopidogrel versus ticagrelol in high-bleeding risk patients presenting with acute coronary syndromes: insights from the multicenter START-ANTIPLATELET registry. Intern Emerg Med. 2020; 15. https://doi.org/10.1007/s11739-020-02404-1.

5. Wallentin L, Becker RC, Budaj A, Cannon CP, Emanuelsson H, Held C, et al. Ticagrelol versus clopidogrel in patients with acute coronary syndromes. N Eng J Med. 2009;361:1045-57.

6. Alexopoulos D, Xanthopoulou I, Deftereos S, Hamilos M, Sitafiolis G, Kanakakis I, et al. Contemporary antiplatelet treatment in acute coronary syndrome patients undergoing coronary intervention: 1-year outcomes from the GReek AntiPlatElet (GRAPE) Registry. J Thromb Haemost. 2016;14:1146-54.

7. Beigel R, Iakobishvili Z, Shlomo N, Segev A, Witberg G, Zahger D, et al. Real-world use of novel $\mathrm{P}_{2} \mathrm{Y}_{12}$ inhibitors with acute myocardial infarction: a treatment paradox. Cardiology. 2017;136:21-8

8. Sadanandan S, Singh IM. Clopidogrel: the data, the experience, and the controversies. Am J Cardiovasc Drugs. 2012;12:361-74.

9. Koyabu Y, Abe S, Sakuma M, Kanaya T, Obi S, Yoneda S, et al. Short-term safety and mid-term efficacy of prasugrel versus clopidogrel in patients undergoing percutaneous coronary intervention. Intern Med. 2019;58:2315-22.

10. Campo G, Miccoli M, Tebaldi M, Marchesini J, Fileti L, Monti $\mathrm{M}$, et al. Genetic determinants of on-clopidogrel high platelet reactivity. Platelets. 2011;22:399-407.

11. Mao L, Jian C, Changzhi L, Dan H, Suihua H, Wenyi T, et al. Cytochrome CYP2C19 polymorphism and risk of adverse clinical events in clopidogrel-treated patients: a meta-analysis based on 23,035 subjects. Arch Cardiovasc Dis. 2013;106:517-27.

12. Zhu B, Zhao Z, McCollam P, Anderson J, Bae JP, Fu H, et al. Factors associated with clopidogrel use, adherence, and persistence in patients with acute coronary syndromes undergoing percutaneous coronary intervention. Curr Med Res Opin. 2011;27:633-41.

13. Pereira NL, Geske JB, Mayr M, Shah SH, Rihal ChS. Pharmacogenetics of clopidogrel: an unresolved issue. Circ Cardiovasc Genet. 2016;9:185-8.

14. Kazui M, Nishiya Y, Ishizuka T, Hagihara K, Farid NA, Okazaki $\mathrm{O}$, et al. Identification of the human cytochrome P450 enzymes involved in the two oxidative steps in the bioactivation of clopidogrel to its pharmacologically active metabolite. Drug Metab Dispos. 2010;38:92-9.

15. Sibbing D, Koch W, Gerhard D, Schuster T, Braun S, Stegherr J, et al. Cytochrome 2C19*17 allelic variant, platelet aggregation, bleeding events and stent thrombosis in clopidogreltreated patients with coronary stent placement. Circulation. 2010;121:512-8.

16. Ma T, Lam YY, Tan V, Kiernan TJ, Yan BP. Impact of genetic and acquired alteration in cytochrome $\mathrm{P} 450$ system on pharmacologic and clinical response to clopidogrel. Pharmacol Ther. 2010;125:249-59. 
17. Zhang Y-J, Li M-P, Tang J, Chen X-P. Pharmacokinetic and pharmacodynamic responses to clopidogrel: evidences and perspectives. Int J Environ Res Public Health. 2017;14:301-19.

18. Brown S-A, Pereira N. Pharmacogenomic impact of CYP2C19 variation on clopidogrel therapy in precision cardiovasular medicine. J Personal Med. 2018;8:8-31.

19. Reny J-L, Combescure C, Daali Y, Fontana D, PON1 meta-analysis group. Influence of the paraoxonase-1 Q192R genetic variant on clopidogrel responsiveness and recurrent cardiovascular events: a systematic review and meta-analysis. J Thromb Haemost. 2012;10:1242-51.

20. Bouman HJ, Schoming E, van Werkum JW, Velder J, Hackeng $\mathrm{ChM}$, Hirschhauser Ch, et al. Paraoxonase-1 is a major determinant of clopidogrel efficacy. Nat Med. 2011;17:110-6.

21. Fontana P, James R, Barazer I, Berdague P, Schved J-F, Rebsamen M, et al. Relationship between paraoxonase-1 activity, its Q192R genetic variant and clopidogrel responsiveness in the ADRIE study. J Thromb Haemost. 2011;9:1664-6.

22. Campo G, Ferraresi P, Marchesini J, Bernardi F, Valgimigli M. Relationship between paraoxonase Q192R gene polymorphism and on-clopidogrel platelet reactivity over time in patients treated with percutaneous coronary intervention. J Thromb Haemost. 2011;9:2106-8.

23. Karaźniewicz-Łada M, Danielak D, Rubiś B, Burchardt P, Komosa $\mathrm{A}$, Lesiak M, et al. Impact of common ABCB1 polymorphism on pharmacokinetics and pharmacodynamics of clopidogrel and its metabolites. J Clin Pharm Ther. 2015;40:226-31.

24. Danielak D, Karaźniewicz-Łada M, Wiśniewski K, Bergus P, Burchardt P, Komosa A, et al. Impact of CYP3A4*1G allele on clinical pharmacokinetics and pharmacodynamics of clopidogrel. Eur J Drug Metabol Pharmacokinet. 2017;42:99-107.

25. Srinivas NR, Mamidi RN. Bioanalytical considerations for compounds containing free sulfhydryl groups. Biomed Chromatogr. 2003;17:285-91.

26. Serebruany V, Cherala G, Williams C, Surigin S, Booze Ch, Kuliczkowski W, et al. Association of platelet responsiveness with clopidogrel metabolism: role of compliance in the assessment of "resistance." Am Heart J. 2009;158:925-32.

27. Vocilkova L, Opatrilova R, Sramek V. Determination of clopidogrel by chromatography. Curr Pharm Anal. 2009;5:424-31.

28. Karaźniewicz-Łada M, Główka F, Oszkinis G. Capillary zone electrophoresis method for determination of (+)-S clopidogrel carboxylic acid metabolite in human plasma and urine designed for biopharmaceutic studies. J Chromatogr B Analyt Technol Biomed Life Sci. 2010;878:1013-8.

29. Robinson A, Hillis J, Neal C, Leary AC. The validation of a bioanalytical method for the determination of clopidogrel in human plasma. J Chromatogr B Analyt Technol Biomed Life Sci. 2007;848:344-54.

30. Bonello L, Tantry US, Marcucci R, Blindt R, Angiolillo DJ, Becker R, et al. Consensus and future directions on the definition of high on-treatment platelet reactivity to adenosine diphosphate. J Am Coll Cardiol. 2010;56:919-33.

31. Gimbel M, Qaderdan K, Willemsen L, Hermanides R, Bergmeijer $\mathrm{T}$, De Very E, et al. Clopidogrel versus ticagrelol or prasugrel in patients aged 70 years or older with non-ST-elevation acute coronary syndrome (POPular AGE): the randomized, open-label, non-inferiority trial. Lancet. 2020;395:1374-81.

32. Olędzki S, Kornacewicz-Jach Z, Safranow K, Kiedrowicz R, Gawrońska-Szklarz B, Jastrzębska M, et al. Variability of platelet response to clopidogrel is not related to adverse cardiovascular events in patients with stable coronary artery disease undergoing percutaneous coronary intervention. Eur J Clin Pharmacol. 2017;73:1085-94.

33. Rouini MR, Ardakani Y, Foroumadi A, Lavasani H, Hakemi L. Sensitive quantification of carboxylic acid metabolite of clopidogrel in human plasma by LC with UV dectection. Chromatographia. 2009;70:953-6.

34. Mitakos A, Panderi I. A validated LC method for the determination of clopidogrel in pharmaceutical preparations. J Pharm Biomed Anal. 2002;28:431-8.

35. Souri E, Jalalizadeh H, Kebriaee-Zadeh A, Shekarchi M, Dalvandi A. Validated HPLC method for determination of carboxylic acid metabolite of clopidogrel in human plasma and its application to a pharmacokinetic study. Biomedical Chromatogr. 2006;20:1309-14.

36. Singh SS, Sharma K, Barot D, Mohan PR, Lohray V. Estimation of carboxylic acid metabolite of clopidogrel in Wistar rat plasma by HPLC and its application to a pharmacokinetic study. J Chromatogr B Analyt Technol Biomed Life Sci. 2005;821:173-80.

37. Mani H, Toennes SW, Linnemann B, Urbanek DA, Schvonberg J, Kauert G, et al. Determination of clopidogrel main metabolite in plasma: a useful tool for monitoring therapy? Ther Drug Monit. 2008;30:84-9.

38. Mega JL, Close SL, Wiviott SD, Shen W, Hockett RD, Brandt JT, et al. Cytochrome p-450 polymorphism and response to clopidogrel. N Engl J Med. 2009;360:354-62.

39. Simon T, Verstuyft C, Mary-Krause M, Quteineh L, Drouet E, Meneveau N, et al. Genetic determinants of response to clopidogrel and cardiovascular events. N Eng J Med. 2009;360:363-75.

40. Li Y, Tang H-L, Hu Y-F, Xie H-G. The gain-of-function variant allele CYP2C19*17: a double-edged sword between thrombosis and bleeding in clopidogrel-treated patients. J Thromb Haemost. 2012;10:199-206.

41. Wang X-Q, Shen Ch-L, Wang B-N, Huang X-H, Hu Z-I, Li J. Genetic polymorphisms of CYP2C19*2 and ABCB1 C3435T affect the pharmacokinetic and pharmacodynamic responses to clopidogrel in 401 patients with acute coronary syndrome. Gene 2015;558: 200-207.

42. Angiolillo DJ, Fernandez-Ortiz A, Bernardo E, Ramírez C, Cavallari $\mathrm{U}$, Trabetti $\mathrm{E}$, et al. Contribution of gene sequence variations of the hepatic cytochrome P450 3A4 enzyme to variability in individual responsiveness to clopidogrel. Arterioscler Thromb Vasc Biol. 2006;26:1895-900.

43. Zhang H-Z, Kim MH, Guo L-Z, Serebruany V. CYP2C19 but not CYP2B6, CYP3A4, CYP3A5, ABCB1, PON1 or P2Y12 genetic polymorphism impacts antiplatelet response after clopidogrel in Koreans. Blood Coagul Fibrinolysis. 2017;28:56-61.

44. Jaitner J, Morath T, Byrne RA, Braun S, Gebhard D, Bernlochner I, et al. No association of ABCB1 C3435T genotype with clopidogrel response or risk of stent thrombosis in patients undergoing coronary stenting. Circ Cardiovasc Interv. 2012;5:82-8.

45. Mega JL, Close SL, Wiviott SD, Man M, Duvvuru S, Walker JR, et al. PON1 Q192R genetic variant and response to clopidogrel and prasugrel: pharmacokinetics, pharmacodynamics, and a meta-analysis of clinical outcomes. J Thromb Thrombolysis. 2016;41:374-83.

Publisher's Note Springer Nature remains neutral with regard to jurisdictional claims in published maps and institutional affiliations. 